Sabin, 1955c). One of us (W. G. K.) also observed that the small epidemic in Kenya in December, 1947, may have acted as a link between the major epidemic in Britain in the autumn of 1947 and that in South Africa in the spring of 1948.

Activation of a dormant strain is rendered possible by the known presence of virulent strains in underdeveloped countries. These give rise to sporadic cases of infantile paralysis and caused a high incidence among troops posted to such areas during the last war.

Mutation in culture is infrequent but does occur (Sabin, 1955d), and has almost certainly occurred in nature during the past 60 years. It is unlikely, however, that a local mutation has been responsible for each one of the very large number of epidemics that have occurred during this period.

\section{Future Outlook}

The probability of further spread of virulent strains with an increase in the number and severity of epidemics can only be described as grave, and will place a great strain on the resources of undeveloped countries in the provision of treatment both for the acute cases and for an increasing number of cripples.

It would appear that this spread will continue unchecked until there has been produced a vaccine which can provide immunity against all known types and which is within the economic means of underdeveloped countries. Work at present being carried out by Koprowski, Sabin, Dick. and others on the production of an oral vaccine of avirulent strains holds out more hope than do the vaccines in current use owing to the possibility of achieving lifelong immunity by the administration of only one dose (Sabin, 1955b). Further economies in administration and in the cost of a campaign would be achieved if a simple test could be devised for the presence of previously developed immunity in individuals.

\section{Summary}

A description is given of an acute localized outbreak of poliomyelitis in a primitive community. The incidence was 99 per 100,000 population, referring to paralytic cases only ; $85 \%$ of these were under the age of 3 and $96 \%$ under 5 .

The conclusion is reached that the epidemic resulted from the appearance of a strain more highly virulent than that normally present, although antigenically similar. The occurrence was not due to any marked improvement in social or hygienic conditions.

An increased demand for curative and orthopaedic services is envisaged in underdeveloped countries. The need for orthopaedic services to care for cripples from previous epidemics will continue for many years after an effective and lifelong vaccine becomes freely available.

We wish to thank the Director of Medical Services, Tanganyika, for permission to publish this paper.

\section{REFERENCES}

British Medical Journal, 1955, 2, 857.

Gear J. H. S. (1955a). In Poliomyelitis, p. 34. W.H.O. Monograph No. 26. Geneva.

(1955b). Ibid., p. 35

McFarlan, A. M., Dick, G. W. A., and Seddon, H. J. (1946). Quart. J. Med., 15, 183

Medical Department, Tanganyika (1954). Annual Report. Government Printer, Dar-es-Salaam

Paul, J. R. (1955a). In Poliomyelitis, p. 20. W.H.O. Monograph No. 26 Geneva.

- (1955b). Ibid., p. 15.

Payne, A. M.-M. (1955a). Ibid., p. 374.

(1955b). Ibid., p. 377

(1955c). Ibid., p. 387.

Poliomyelitis (1955). W.H.O. Monograph No. 26. Geneva. 246

Rhodes, A. J., Wood, W., and Du

Sabin, A. B. (1955a). Ibid., p. 314. 3 . 160

- (1955c) In Poliomyelitis, p. 313. W.H.O. Monograph No. 26 (1955c)

\section{ETHYLENE GLYCOL POISONING WITH MENINGOENCEPHALITIS AND ANURIA}

BY

IAN P. ROSS, M.D., M.R.C.P.

Late Captain, R.A.M.C.; Medical Registrar, the London Hospital

The purpose of this paper is to record and comment on the features of ethylene glycol poisoning as seen in a patient exhibiting meningoencephalitis and anuria, resulting in death after 12 days. In most cases of poisoning death ensues rapidly, and only a small minority survive the initial phase and die later from renal failure.

Ethylene glycol is a clear, colourless, odourless liquid with a bitter-sweet taste, and produces a sense of warmth when drunk. It has the formula $\mathrm{HOCH}_{2}-\mathrm{CH}_{2} \mathrm{OH}$, a boiling-point of $197^{\circ} \mathrm{C}$., is heavier than water, and evolves heat when mixed with it. Ethylene glycol is one particular substance from a whole series of glycols, and chemically it occupies a position between ethyl alcohol and glycerol. Its main uses are as antifreeze agent, as a solvent, and in electrolytic condensers. The properties, uses, and animal toxicity have been fully reported by Hanzlik et al. (1931) and Browning (1952).

Human poisoning with it has been known for about 30 years. Most cases have occurred as a result of drinking "antifreeze," and this has been especially common among Service personnel ; it has been taken by accident, but has often been drunk as a substitute for alcohol. Series of fatal cases have been reported by Boemke (1943), Pons and Custer (1946), Kahn and Brotchner (1950), Smith (1951), and others.

\section{Case Report}

At 4 p.m. on February 4, 1953, a healthy man of 33 was seen to drink $\frac{1}{4}-\frac{1}{2}$ pint $(140-280 \mathrm{ml}$.) of antifreeze solution containing almost pure ethylene glycol. Five hours later he appeared ill and became drowsy; he was put to bed and slept peacefully. The next day he was very drowsy, and by noon was in a coma ; the temperature was $95^{\circ} \mathrm{F}$. $\left(35^{\circ} \mathrm{C}\right.$.), pulse rate 80 , respiratory rate 20 , and blood pressure $110 / 70$. At this time the reflexes were brisk and equal and the plantar responses flexor. Eight hours later he was less drowsy, but was delirious, and reacted to painful stimuli but not to commands. Bruises were noted on the armis and legs. The temperature had risen to $102^{\circ} \mathrm{F}$. $\left(38.9^{\circ} \mathrm{C}\right.$.) and the blood pressure to $160 / 80$, the pulse and respiratory rates being almost unchanged. There was some twitching of the face and arms, and moderate neck rigidity. The pupils were small and equal in size, and responded sluggishly to light. The remainder of the nervous system was normal, but there was incontinence of urine. A lumbar puncture showed a slightly turbid cerebrospinal fluid (C.S.F.) under increased pressure. Analysis showed $400 \mathrm{mg}$. of protein and $30 \mathrm{mg}$. of glucose per $100 \mathrm{ml}$. The total cell count was 695 cells per c.mm. (80\% polymorphs, $20 \%$ lymphocytes). A blood count showed a haemoglobin of $96 \%$ and a total white-cell count of 28,000 ( $85 \%$ polymorphs).

On February 6 he was restless but less drowsy, and his temperature was $99^{\circ} \mathrm{F}$. $\left(37.2^{\circ} \mathrm{C}\right.$. $)$. He had taken fluids by mouth, but had vomited a little. There was less neck rigidity, but the twitching persisted in the face and also in the arms, which were now adducted and flexed. The limb reflexes were very brisk, the abdominal reflexes absent, and the plantar responses extensor; there was bilateral knee and ankle clonus. The liver was felt one fingerbreadth below the costal margin. As he had passed no more urine, he was catheterized and $150 \mathrm{ml}$. of turbid amber urine of S.G. 1012 obtained. This contained one-eighth volume of albumin but was otherwise normal; there were a few leucocytes in 
the deposit but no red cells. The total white blood cell count was now 21,000. A radiograph of the chest was normal. Because of the oliguria the glucose and arachis oil regime (Bull et al., 1949) was begun.

On February 7 he seemed to have improved a little more, although the physical signs were unchanged. He had passed no more urine. The blood urea was $165 \mathrm{mg}$. per $100 \mathrm{ml}$., the blood sugar and serum bilirubin being normal. A lumbar puncture showed that the C.S.F. pressure had returned to normal, and that the protein had fallen to $120 \mathrm{mg}$. per $100 \mathrm{ml}$. and the cells to 40 lymphocytes per c.mm. On February 8 his condition was much the same, but the liver had enlarged slightly. Only $6 \mathrm{ml}$. of urine (S.G. 1010) was obtained by catheter; it contained the same amount of albumin as before. The following day his mental state improved, and $60 \mathrm{ml}$. of urine was obtained; this contained one-eighth volume of albumin.

On February 10 he was rational but had retrograde amnesia. The muscular twitching was less. Muscular power was good, and the reflexes were still brisk and equal; the plantar responses were extensor. The blood pressure had risen to $180 / 115$ and the heart was slightly enlarged. $120 \mathrm{ml}$. of urine containing three-eighths volume of albumin was obtained. The blood urea was $181 \mathrm{mg}$. per $100 \mathrm{ml}$. On February 11 there was further slight improvement, and the $120 \mathrm{ml}$. of urine obtained contained a little less albumin. The haemoglobin was $88 \%$. On February 12 his mental and physical state improved greatly, the blood pressure rose still further to $200 / 115$, and the $350 \mathrm{ml}$. of urine obtained (S.G. 1010) contained one-tenth volume of albumin. The next day the C.S.F. contained $50 \mathrm{mg}$. of protein per $100 \mathrm{ml}$. and 8 cells per c.mm. The blood urea was $330 \mathrm{mg}$. per $100 \mathrm{ml}$.

On February 14 he complained of abdominal pain and began to vomit. Then he developed heart failure, and, although the urinary output rose to $540 \mathrm{ml}$., his condition deteriorated and he died two days later after 12 days' illness.

Necropsy.-The body was that of a slightly wasted man. The most marked changes were in the kidneys, both being enlarged and each weighing $245 \mathrm{~g}$. The capsules stripped easily from smooth surfaces. The cortex was widened, showing vertical linear alternate red and brown striations; the medulla appeared normal. The pelvis showed slight congestion, but no haemorrhages were seen. The bladder appeared normal. The liver was enlarged and weighed $1,855 \mathrm{~g}$. The cut surface was pale brown and showed small paler areas up to $0.2 \mathrm{~cm}$. diameter scattered generally throughout its substance, the whole pattern being rather indistinct. The right heart was dilated, and there was slight hypertrophy of the left ventricle, the wall being $1.8 \mathrm{~cm}$. thick. The endocardium was a pale blotchy reddish brown. In the respiratory system the trachea and bronchi were full of frothy serous fluid. The lungs were heavy and voluminous, exuding much serous fluid from their cut surfaces. There was patchy bronchopneumonic consolidation in the right lower lobe. A few subpleural petechiae were present. The brain and meninges revealed diffuse congestion but no focal lesion. The stomach and intestines appeared normal. There was a haemorrhage 3 by 2 by $1 \mathrm{~cm}$. over the head of the pancreas. The spleen was soft and enlarged $(235 \mathrm{~g}$.). No abnormality was seen in the pituitary, adrenals, or thyroid.

Microscopical Examination.-In the kidneys the tubular cells showed swelling, granularity, hydropic degeneration, a few pyknotic nuclei, and occasional loss of nuclei. A few tubules seemed to be completely necrotic; the lumen of the tubules contained acidophil debris, but a careful search revealed only very scanty sheaf-shaped crystals. A few glomeruli showed proliferative changes and capsular adhesions, but most appeared normal. The interstitial tissue was pale-staining and oedematous, and showed a slight infiltration with lymphocytes. These changes were more marked in the cortex than in the medulla. The arteries appeared normal. The liver showed vacuolation of the cells at the centres of the lobules, and a few central cells appeared necrotic, with pyknotic nuclei. The meninges on the sections seen were normal. The myocardium showed parenchymatous degeneration. The lungs revealed oedema, a few alveolar haemorrhages, and focal acute inflammation. Death was thought to be due to acute heart failure and to renal failure due to ethylene glycol poisoning.

\section{Discussion}

The fatal dose of ethylene glycol is variable; Bachem (1917) drank $45 \mathrm{~g}$. with no ill effect, Page (1927) drank $15 \mathrm{ml}$. and noted only a sense of warmth, Kahn and Brotchner (1950) reported recovery after $240 \mathrm{ml}$., and Hunt (1932) assessed the minimal lethal dose at $100 \mathrm{ml}$.; death usually occurs with doses between 200 and $400 \mathrm{ml}$., for more than this seems to be universally fatal. Poisoning by ethylene glycol vapour has been reported by Troisi (1950).

The toxic effects are most marked on the nervous system, lungs, and kidneys. Of the fatal cases recorded in the literature, death has occurred in over $93 \%$ within 72 hours from oedema of the lungs and cerebral damage; albuminuria and oliguria have been noted in such cases, but have played little part in causing death. The present case is among a small number, only five others having been found in the literature, in which there was recovery from the initial phase and death later, after one to two weeks, from renal failure. A small number of patients recover completely.

The manifestations of ethylene glycol poisoning in the nervous system are due to the production of a chemical meningoencephalitis. The clinical features of encephalitis are more obvious in those patients surviving a few days than in those dying in progressive coma. Both in the present case and in those described by Widman (1946) there was a latent interval of 5-12 hours before the development of symptoms. The early drowsiness, slurring of speech, and ataxia have been frequently and mistakenly attributed to alcohol. The drowsiness develops and progresses into coma which is often accompanied by shock, low blood pressure, and subnormal temperature. In less severe cases the drowsiness is associated with restlessness and ataxia. In most cases oedema of the lungs ensues, followed by death (Pons and Custer, 1946). When the stage of shock improves, symptoms and signs of meningoencephalitis appear.

Brekke (1930) and Hansen (1930) recorded ocular-nerve palsies, but none were observed here. Twitching was observed, but convulsions have been uncommon in recorded cases except as a terminal event. Within 72 hours the present case showed evidence of bilateral pyramidal tract damage, which subsequently improved. Few C.S.F. studies have been undertaken. Pons and Custer (1946) noted that the C.S.F. could be clear or blood-tinged, and Grant (1952) that the cells and protein were increased. These findings are remarkable in that they are unusual in cases of chemical poisoning. The C.S.F. changes here appear to be unique in that they show the rapid and considerable improvement that may take place from the ethylene glycol encephalitis in 10 days. Recovery from encephalitis has been described, but careful follow-up for long-term effects are few. Grant (1952) records changes in personality present after two and a half years. The pathological changes in the brain include oedema, congestion, and haemorrhages (Boemke, 1943).

The renal damage produced by ethylene glycol is well recognized, but in acute poisoning with early death it is not a prominent clinical feature. With initial survival the renal effects are of particular importance. This damage is seldom recognized for 24 hours or longer, and then may be recognized because of albuminuria, oliguria, or anuria. The albuminuria varies from a haze of albumin up to one-fifth volume. Fixation of the specific gravity is an important finding in patients surviving a few days. The urinary deposit contains casts and a few leucocytes; red cells were absent in the present case, though several observers have noted them, though rarely to the extent of macroscopic haematuria.

The development of oliguria or anuria is related to the severity of the poisoning; each may continue, resulting in 
progressive uraemia with a fatal issue, but survival is possible if sufficient diuresis occurs within 14-21 days (Kahn and Brotchner, 1950). In the present case some recovery did occur, but not sufficient to be effective, and the blood urea continued to rise, reaching $330 \mathrm{mg}$. per $100 \mathrm{ml}$. by the tenth day. The renal damage is attributable to tubular damage, the debatable issue being whether this is due to the ethylene glycol or to the oxalic acid produced by breakdown of the glycol. Hanzlik et al. (1931) is of the opinion that oxalic acid plays little part in the production of the renal damage - since the conversion rate of ethylene glycol to oxalic acid is of a very low order, about $2 \%$ - and that considerable oxaluria can occur with no evidence of renal damage. The pathological changes are those of a tubular degeneration, and the presence of many oxalate crystals is of help in pathological diagnosis in the acute deaths, but with delayed death they tend to disappear.

The frequency of the development of hypertension in association with the renal lesion is difficult to assess. Several observers noted mild hypertension in the acute fatal cases. Cases surviving one to three weeks have been recorded so infrequently that any definite statement on the question of hypertension is unwise; however, in the present case and that of Smith (1951) definite hypertension seems to have developed. In acute fatal poisoning, changes in the liver have been described by Smith (1951), Kahn and Brotchner (1950), and Boemke (1943), these consisting of hydropic degeneration, pyknotic nuclei, and some lymphocytic infiltration. In patients surviving the initial episodes, and dying later of renal failure, liver damage has not been prominent. Jaundice has not been recorded; slight hepatomegaly was noted in the case recorded here. Liver-function tests have not been recorded in fatal cases, though these were normal in a patient who survived (Kahn and Brotchner, 1950).

A polymorphonuclear leucocytosis (it was 28,000 per c.mm. in the present case) has previously been noted in acute cases ; with recovery it dropped towards normal, 16,000 on the eighth day. Although Von Oettingen and Jirouch (1931) noted an in vitro haemolytic action of ethylene glycol, this has not been noted in patients dying of poisoning early or late. The present patient had a haemoglobin of $96 \%$ on the second day and $88 \%$ on the eighth day, together with a normal serum bilirubin on the fourth day; this does not suggest any serious haemolytic effect.

The subperitoneal haemorrhage in the region of the pancreas is interesting; it could be related to the hypertension, but may well be related to the pancreas, for Smith (1951) noted a subacute focal pancreatitis.

\section{Summary}

The properties, uses, and toxicity of ethylene glycol are stated.

A case of poisoning is presented in which acute meningoencephalitis was followed by anuria and death from renal failure after 12 days.

The morbid anatomical findings are described.

The variations in the clinical picture are discussed.

I should like to thank Dr. Donald Hunter for his advice and the Director-General of the Army Medical Services for permission to publish.

REFERENCES

Bachem, C. (1917). Med. Klin., 13, 7, 312

Boemke, F. (1943). Virchows Arch. path. Anat., 310, 106

Brekke, A. (1930). Norsk Mag. Lagevid., 91, 18. revised ed., p. 340 . London.

Bull, G. M., Joekes, A. M., and Lwwe, K. G. (1949). Lancet, 2, 229

Grant, A. P. (1952). Ibid., 2, 1252.

Hansen, K. (1930). Samml. Vergiftungsf., 1, 175

Hanzlik, P. J., Seidenfeld. M. A., and Johnson, C. C. (1931). J. Pharmacol. 41, 387.

Hunt, R. (1932). Industr. Engng. Chem., 24, 361, 836.

Kahn, H. S., and Brotchner, R. J. (1950). Ann. intern. Med. 32, 284

Page, I. H. (1927). J. Pharmacol., 30, 313

Pons, C. A., and Custer, R. P. (1946). Amer. J. med. Scl., 211, 544.

Smith, D. E. (1951). A.M.A. Arch. Path., 51, 423.

Troisi, F. M. (1950). Brit. J. industr. Med., 7, 65.

Von Oettingen, W. F., and Jirouch, E. A. (1931).

Widman, C. (1940. Acta med. scand., 126, 295.

\section{Medical Memoranda}

\section{Atypical Weil's Disease}

A toxic confusional state in Weil's disease is exceptional, and in a case of Weil's disease without jaundice the development of delirium is rare. The following case is an example of the latter condition, and is reported because it raises a diagnostic difficulty.

\section{CASE REPORT}

A man aged 58 was admitted to hospital on January 9, 19.55. His illness began six days previously with shivering and pains in the limbs. The following day diarrhoea occurred, and persisted for three days. On the day of admission he developed pain in the right renal angle. He vomited for several days at the onset.

On examination he was drowsy and confused. His temperature was $102^{\circ} \mathrm{F} .\left(38.9^{\circ} \mathrm{C}.\right)$. The tongue was moist. There was no icterus or anaemia. The pulse was 98 and irregularly irregular. The blood pressure was $98 / 65$. No cardiac murmurs were audible. No abdominal tenderness or enlargement of abdominal viscera was present. No abnormal neurological findings were detected and he had no signs of meningeal irritation. Examination of the cerebrospinal fluid gave a normal result. On January 11 the blood urea was $224 \mathrm{mg}$. per $100 \mathrm{ml}$. One week later it had fallen to $60 \mathrm{mg}$. per $100 \mathrm{ml}$. The urine contained no abnormal constituents. The conjunctivae were injected. Two days after admission he developed keratitis profunda with vascularization of the cornea. A tentative diagnosis of Weil's disease was made and antibiotics and intravenous fluids were given.

During the next eight days he remained drowsy and somewhat confused. There was no evidence of icterus at any stage of the illness. On the ninth day he became very garrulous, noisy, and restless. He was disorientated in time and place. He remained in this condition for 36 hours, then gradually became less confused. Ten days later he was rational and well-behaved. At this stage he had no clear recollection of his conduct during the first 10 days in hospital.

Leptospirosis was proved by agglutination tests. The Leptospira icterohaemorrhagiae agglutination was positive at $1 / 300$ on January 18 and two weeks later was positive at $1 / 10,000$.

\section{COMMENT}

It is widely recognized that jaundice is not an essential feature of Weil's disease. It is generally agreed that the cases which do not develop jaundice are mild and run a benign course. In the case described mental symptoms were the predominant clinical feature. On account of the absence of jaundice throughout the illness it is unlikely that cholaemia played any significant part. The blood urea was high at the onset of illness, but it had fallen to a level just above normal at the time of the acute delirium. One can therefore conclude that extrarenal uraemia was not a factor in the causation of the delirium. The severe impairment of renal function in the absence of albuminuria is difficult to explain.

The conclusion is that Weil's disease should be considered as a possible cause of an acute organic reaction psychosis even in the absence of jaundice. Unless laboratory investigations are made the true nature of the illness will remain unrecognized.

I am indebted to Dr. C. R. Murdock, Central Laboratory, Northern Ireland Hospitals Authority, for his report on the agglutination tests. 